\title{
In Situ Production of Zoospores by Five Species of Phytophthora in Aqueous Environments for Use as Inocula
}

G. A. Ridge and S. N. Jeffers, School of Agricultural, Forest, and Environmental Sciences; W. C. Bridges, Jr., Department of Mathematical Sciences; and S. A. White, School of Agricultural, Forest, and Environmental Sciences; Clemson University, Clemson, SC 29634 \begin{abstract}
environments for use as inocula. Plant Dis. 98:551-558.
The goal of this study was to develop a procedure that could be used to evaluate the potential susceptibility of aquatic plants used in constructed wetlands to species of Phytophthora commonly found in nurseries. V8 agar plugs from actively growing cultures of three or four isolates of Phytophthora cinnamomi, P. citrophthora, P. cryptogea, $P$. nicotianae, and $P$. palmivora were used to produce inocula. In a laboratory experiment, plugs were placed in plastic cups and covered with $1.5 \%$ nonsterile soil extract solution (SES) for 29 days, and zoospore presence and activity in the solution were monitored at 2- or 3-day intervals with a rhododendron leaf disk baiting bioassay. In a greenhouse experiment, plugs of each species of Phytophthora were placed in plastic pots and covered with either SES or Milli-Q water for 13 days during both summer and winter months, and zoospore presence in the solutions were monitored at 3-day intervals with the baiting bioassay and by filtration. Zoospores were present in solutions throughout
\end{abstract}

Abstract

Ridge, G. A., Jeffers, S. N., Bridges, W. C., Jr., and White, S. A. 2014. In situ production of zoospores by five species of Phytophthora in aqueous

the 29-day and 13-day experimental periods but consistency of zoospore release varied by species. In the laboratory experiment, colonization of leaf baits decreased over time for some species and often varied among isolates within a species. In the greenhouse experiment, bait colonization decreased over time in both summer and winter, varied among species of Phytophthora in the winter, and was better in Milli-Q water. Zoospore densities in solutions were greater in the summer than in the winter. Decreased zoospore activities for some species of Phytophthora were associated with prolonged temperatures below 13 or above $30^{\circ} \mathrm{C}$ in the greenhouse. Zoospores from plugs were released consistently in aqueous solutions for at least 13 days. This procedure can be used to provide in situ inocula for the five species of Phytophthora used in this study so that aquatic plant species can be evaluated for potential susceptibility.
Species of Phytophthora cause some of the most frequently occurring and economically important diseases of ornamental crops throughout the world, and Phytophthora root and crown rots and foliage blights cause extensive losses during production in nurseries, particularly to woody landscape plants $(1,6,21)$. Furthermore, exotic species of Phytophthora are a threat to natural ecosystems and already have had a devastating impact on the eucalyptus forests of Australia (caused by Phytophthora cinnamomi) and the coastal forests in California and southwestern Oregon (caused by $P$. ramorum $)(23,25,29)$. In North America, the danger $P$. ramorum poses to red oak forests in the eastern United States is a major concern $(17,25)$ because $P$. ramorum can survive temperatures of 2 to $26^{\circ} \mathrm{C}(9)$ and has been found on plants in nurseries and natural ecosystems from British Columbia to southern California (21). Complicating quarantine and management efforts for P. ramorum and other species of Phytophthora are the presence of several sources of inocula in nurseries, which include many different host plant species, infested soils, container substrates, and irrigation and production runoff water that can facilitate pathogen movement and dispersal $(1,6,7,21,25)$.

Vegetated buffers and constructed wetlands are ecologically based treatment options that effectively remove both nutrient and

\section{Corresponding author: S. A. White, E-mail: swhite4@ clemson.edu}

Technical contribution number 6142 of the Clemson University Experiment Station. This material is based upon work supported by the United States Department of Agriculture NIFA under project numbers SC-1700398 and SC-1700309.

Accepted for publication 5 November 2013.

http://dx.doi.org/10.1094/PDIS-06-13-0591-RE

(C) 2014 The American Phytopathological Society chemical contaminants from runoff water at ornamental plant nurseries $(26,28)$. However, methods of water treatment that utilize wetland plants could become sources of inocula if the plant material used in these systems serve as an alternative host for species of Phytophthora. Thus, when installing vegetated buffers or constructed wetlands at a nursery, it would be prudent to utilize plant species that are not susceptible to and do not harbor Phytophthora spp.; however, only limited information is available on the susceptibility of wetland plants to these ubiquitous plant pathogens.

There is an abundance of literature pertaining to pathogenicity of and plant susceptibility to species of Phytophthora (6), with most studies employing long-standing methods of inoculation using laboratory-produced propagules (e.g., zoospores, oospores, and chlamydospores) or some type of colonized substrate (e.g., agar plugs, vermiculite [24], or rice grains [10]). These procedures have been developed primarily to evaluate susceptibility of plants growing in soil or a soilless substrate and may not be sufficient to characterize the potential for infection by zoospores in infested runoff at a nursery.

Therefore, the objective of this study was to develop a procedure to produce inocula of Phytophthora spp. in situ that would be similar to the inocula found in nursery effluent so that wetland plants could be exposed to a continuous supply of zoospores in an aqueous environment. This procedure then could be used to evaluate potential susceptibility of wetland plants to species of Phytophthora under experimental conditions. The procedure should be effective for multiple species of Phytophthora under the different environmental conditions that occur throughout the year. Preliminary results have been reported (22).

\section{Materials and Methods}

Phytophthora spp. Five species of Phytophthora commonly found in nurseries in the southeastern United States were selected for this study: $P$. cinnamomi, $P$. citrophthora, $P$. cryptogea, $P$. nicotianae, and $P$. palmivora $(1,4,18,19)$. Three isolates of each species 
(all from a permanent collection maintained in the laboratory of S. N. Jeffers at Clemson University) were used for all experiments conducted. All 15 isolates were recovered from diseased ornamental plants in South Carolina that were submitted to the Clemson University Plant Problem Clinic between 1997 and 2010 (Table 1). A fourth isolate of $P$. citrophthora also was used; this isolate was collected from the roots of Sagittaria latifolia, a wetland plant growing in a vegetated runoff channel at a nursery in Georgia (Table 1). Active cultures of all isolates were maintained on PARPHV8, a medium selective for species of Phytophthora (7).

Isolate characterization. The identities of the 16 isolates of Phytophthora spp. used in this study were confirmed using selected phenotypic characteristics (oospore production and sporangium morphology) and molecular diagnostics (restriction fragment length polymorphism [RFLP] and sequence analysis of the nuclear ribosomal internal transcribed spacer [ITS] region).

Morphological characteristics. To produce oospores, isolates were grown on super-clarified V8 juice agar $(\mathrm{scV} 8 \mathrm{~A} ; 14)$ at $20^{\circ} \mathrm{C}$ in the dark for 6 weeks. Isolates that produced oospores were classified as homothallic and those that did not produce oospores were classified as heterothallic. To produce sporangia, isolates were grown on $10 \% \mathrm{~V} 8$ juice agar (V8A; $100 \mathrm{ml}$ of V8 juice, $1 \mathrm{~g}$ of $\mathrm{CaCO}_{3}, 15 \mathrm{~g}$ of Bacto agar, and $900 \mathrm{ml}$ of distilled water) for 3 to 5 days in the dark at $20^{\circ} \mathrm{C}$. Plugs $(5 \mathrm{~mm}$ in diameter) from the advancing margin of a colony were transferred to a $60-\mathrm{mm}$-diameter petri dish and covered with $1.5 \%$ nonsterile soil extract solution (SES; 13). Petri plates were placed under continuous fluorescent light at room temperature $\left(22\right.$ to $25^{\circ} \mathrm{C}$ ) and sporangia were examined after 12 to $24 \mathrm{~h}$.

Molecular diagnostics. Mycelium mats of each isolate were grown in $10 \%$ clarified V8 broth $(\mathrm{cV} 8 \mathrm{~B} ; 100 \mathrm{ml}$ of buffered and clarified V8 juice [7] and $900 \mathrm{ml}$ of distilled water) for 5 days at $20^{\circ} \mathrm{C}$ in the dark, and then mats were harvested by vacuum filtration, rinsed with distilled water, and frozen at $-20^{\circ} \mathrm{C}$ (3). Total DNA was extracted using a modified protocol for the DNeasy Plant Mini Kit (Qiagen Inc.), and polymerase chain reaction (PCR) was conducted using universal primers ITS 4 and ITS 6 (2,3). A RFLP fingerprint for each isolate was obtained using restriction enzymes $A l u \mathrm{I}$ and $M s p \mathrm{I}$ (5). In addition, PCR products from all isolates were purified and then submitted to the Clemson University Genomics Institute for Sanger sequencing, and sequences were compared and matched with sequences of isolates deposited in the Phytophthora Database at Pennsylvania State University (20).
Zoospore production. For all experiments, isolates initially were grown on $\mathrm{cV} 8 \mathrm{~A}$ to ensure culture purity and then on V8A at $25^{\circ} \mathrm{C}$ in the dark for 3 to 4 days to produce actively growing colonies for sporangium production. A disinfested cork borer was used to cut agar plugs ( $5 \mathrm{~mm}$ in diameter) containing actively growing hyphae from the advancing edge of a colony. V8A plugs were placed on the bottom of containers and covered with an aqueous solution to stimulate natural production of sporangia and subsequent release of zoospores.

Laboratory experiment. A laboratory experiment was conducted to determine the consistency and duration of zoospore release from colonized V8A plugs. The experiment utilized a randomized complete block design with one replicate of each treatment in each of three blocks. Treatments consisted of V8A plugs from an isolate of one of the five species of Phytophthora. Nine agar plugs from one isolate were placed on the bottom of a 260-ml clear plastic cup. Each cup was a replicate; thus, there were three replicate cups per treatment. This experiment was conducted twice as trials one and two.

Each cup was filled with $150 \mathrm{ml}$ of SES $(7,13)$ and placed on one of three trays (blocks) in racks in the laboratory at ambient light $\left(4.55 \pm 1.0 \mu \mathrm{mol} \mathrm{m} \mathrm{m}^{-2} \cdot \mathrm{s}^{-1}\right)$ and temperature. Average daily temperatures were $21.6 \pm 0.9$ to $26.4 \pm 0.8^{\circ} \mathrm{C}$ in trial 1 and $20.5 \pm$ 0.4 to $24.1 \pm 0.5^{\circ} \mathrm{C}$ in trial 2. Cups were monitored for 28 days after the experiment was initiated; therefore, each trial lasted 29 days. On the second day of each trial, six leaf disks $(5 \mathrm{~mm}$ in diameter) from Rhododendron catawbiense 'English Roseum' were floated on the surface of the SES in each cup. In trial 1, leaf disks were removed and replaced every 2 days; in trial 2, leaf disks were removed and replaced every 3 days. After removal, leaf disks were blotted dry and embedded in PARPH-V8 selective medium, and plates were held at $25^{\circ} \mathrm{C}$ in the dark for 24 to $30 \mathrm{~h}$. Leaf disks were examined microscopically ( $\times 30$ to 70$)$ and the presence of zoospores in solutions was confirmed based on mycelium growth from colonized leaf disks. The extent of colonization was quantified using a rating scale ( 0 to 5 ) based on the percentage of the perimeter of each disk from which mycelium grew (Table 2).

Greenhouse experiment. Zoospore production in aqueous environments was evaluated in a greenhouse to determine the impact of environmental conditions at different times of the year because future experiments utilizing this procedure will be conducted in a greenhouse to evaluate wetland plants for potential susceptibility to these species of Phytophthora. The same five species and isolates of Phytophthora were used and two types of aqueous solution were

Table 1. Sources of 16 isolates of five species of Phytophthora used in this study ${ }^{y}$

\begin{tabular}{|c|c|c|c|c|}
\hline Species, isolate number & Host plant & Isolated from & County ${ }^{z}$ & Location \\
\hline \multicolumn{5}{|l|}{ Phytophthora cinnamomi } \\
\hline SC.02-0912 & Itea virginica 'Little Henry' & Roots & Pickens & Landscape \\
\hline SC.02-1054 & Rosa banksiae & Roots & Lexington & Landscape \\
\hline SC.10-0053 & Viburnum obovatum & Roots & Hampton & Landscape \\
\hline \multicolumn{5}{|l|}{ P. citrophthora } \\
\hline SC.97-0673 & Rosa hybrid 'Livin Easy' & Roots & Berkeley & Nursery \\
\hline SC.07-0248 & Rosa hybrid 'Home Run' & Roots & York & Nursery \\
\hline SC.07-0303 & Heuchera hybrid 'City Lights' & Crown & Aiken & Nursery \\
\hline S.lat 3.5 & Sagittaria latifolia & Roots & Grady, GA & Nursery \\
\hline \multicolumn{5}{|l|}{ P. cryptogea } \\
\hline SC.03-0222 & Dicentra hybrid 'King of Hearts' & Roots & York & Nursery \\
\hline SC.05-0491 & Sedum spurium & Stem & Yor & Nursery \\
\hline SC.06-0989 & Euphorbia amygdaloides & Roots & Aiken & Nursery \\
\hline \multicolumn{5}{|l|}{ P. nicotianae } \\
\hline SC.05-0690 & Hibiscus paramutabilis $\times$ syriacus 'Lohengrin' & Stem & Edgefield & Nursery \\
\hline SC.06-0496 & Perovskia sp. & Roots & York & Nursery \\
\hline SC.07-1391 & Rosa hybrid 'The Fairy' & Roots & Berkeley & Nursery \\
\hline \multicolumn{5}{|l|}{ P. palmivora } \\
\hline SC.98-0092 & Pinckneya pubens & Roots & Aiken & Nursery \\
\hline SC.98-0177 & Juniperus sp. & Roots & Charleston & Landscape \\
\hline SC. $02-0875$ & Nerium oleander & Roots & Georgetown & Landscape \\
\hline
\end{tabular}

${ }^{y}$ Isolates from South Carolina were recovered from samples submitted to the Clemson University Plant Problem Clinic. Isolate S.lat 3.5 was isolated by

G. A. Ridge. All isolates are maintained in a permanent collection at Clemson University.

${ }^{\mathrm{z}}$ All counties are in South Carolina, except one in Georgia (GA). 
compared. The experiment utilized a randomized complete block design with three replicate containers for each treatment, with one replicate in each of three blocks.

Zoospore production by the five species of Phytophthora was compared in two aqueous solutions: Milli-Q (EMD Millipore Corporation) water and SES. Each 15 liters of either solution was amended with $0.30 \mathrm{~g}$ of 20-2-20 nitrate-special water-soluble fertilizer (Southern Agricultural Insecticides, Inc.). Large batches of SES were made by mixing $225 \mathrm{~g}$ of soil in 15 liters of Milli-Q water for $1 \mathrm{~h}$; the soil used for SES was tested with a baiting bioassay before use to ensure that it was free of Phytophthora spp.

The effect of season on zoospore production was investigated by conducting two trials in summer and two trials in winter months (i.e., four trials in all). The duration of each greenhouse trial was 13 days, based on results from the laboratory experiment. The two summer trials were conducted from 21 August to 3 September 2011 and from 6 to 18 September 2012. The two winter trials were conducted from 1 to 14 December and 8 to 22 December 2011.

Fifteen 1.9-liter nursery containers (Amerikan Nursery Products, Inc.) were filled with each solution, and 9 or 12 V8A plugs with active mycelium, all of one species, were placed in the bottom of a container: 3 plugs from each of three isolates of $P$. cinnamomi, $P$. cryptogea, $P$. nicotianae, and $P$. palmivora and from each of four isolates of $P$. citrophthora. On the second day of each trial, all containers were assayed for zoospores by floating six rhododendron leaf disks ( $5 \mathrm{~mm}$ in diameter) on the surface of the aqueous solution. After 3 days, leaf disks were removed, blotted dry, and embedded in PARPH-V8 medium, and isolation plates were held at $25^{\circ} \mathrm{C}$ in the dark for 1 day. The presence of zoospores in each container was verified by examining leaf disks for growth of hyphae of Phytophthora spp., and bait colonization was quantified using the 0 -to-5 rating scale described previously (Table 2). After disks were removed, six fresh leaf disks were added to each container, and this process was continued over the 13-day exposure period.

In addition to the baiting bioassay, zoospore densities in solutions were monitored directly by filtration in three of the four trials (12): the second summer trial and both winter trials. Two 25-ml aliquots of water from each pot were filtered on days 4, 7, and 13 and each aliquot was passed through a 47-mm-diameter membrane filter with 5- $\mu \mathrm{m}$ pores (Durapore SVLP04700; Millipore Corporation) under vacuum. Filters were inverted on PARPH-V8 medium and plates were held at $20^{\circ} \mathrm{C}$ in the dark. Approximately $100 \mathrm{ml}$ of aqueous solution was added to each container after aliquots were collected to replace liquid removed for filtration and lost to evaporation. After 2 days, filters were removed, the agar surface was rinsed under running tap water, and colonies of Phytophthora spp. were counted. Zoospore densities were quantified as the number of CFU in $25 \mathrm{ml}$.

Statistical analyses. Data were analyzed using factorial analysis of variance (ANOVA) techniques to determine whether the main effects and interactions of isolate, species of Phytophthora, solution (Milli-Q water and SES), and exposure period (i.e., time = days after inocula were added) influenced the percentages of leaf

Table 2. Rating scale used to quantify the amount of the perimeter of a rhododendron leaf disk colonized by Phytophthora spp.

\begin{tabular}{ccc}
\hline Value & Perimeter colonized $(\%)^{\mathbf{y}}$ & Midpoint value $(\%)^{\mathbf{z}}$ \\
\hline 0 & None & 0 \\
1 & $1-25$ & 12.5 \\
2 & $26-50$ & 38.5 \\
3 & $51-75$ & 63.5 \\
4 & $76-99$ & 88.5 \\
5 & 100 & 100 \\
\hline
\end{tabular}

y Estimated amount of the perimeter on a leaf disk, $5 \mathrm{~mm}$ in diameter, from which hyphae of Phytophthora spp. grew. Leaf disks, which were used to bait Phytophthora spp. in aqueous solutions, were blotted dry and then embedded in PARPH-V8 selective medium; isolation plates were placed at $25^{\circ} \mathrm{C}$ in the dark for 24 to $30 \mathrm{~h}$. Leaf disks were observed at $\times 20$ to 40 .

${ }^{\mathrm{z}}$ Midpoint value for each range that was used in statistical analyses. disk perimeters colonized. The ANOVA tests were adjusted for random effects (blocks and disks) and repeated measures over time. If interactions were found to be significant, simple effects of individual treatments were evaluated. When main effect or simple effects were found to be significant, treatment means were separated using Fisher's least significant difference. All hypothesis tests were conducted with $\alpha=0.05$. Data were analyzed using JMP v.10.0 software (SAS Institute).

\section{Results}

In both the laboratory and greenhouse experiments, colonization of leaf disk baits floating on the surface of aqueous solutions served as a direct indication that zoospores had been released from sporangia produced on the agar plugs placed on the bottom of containers (i.e., plastic cups and nursery containers, respectively); agar plugs did not float and remained submerged throughout each trial. In addition, the mean percentage of the perimeter of leaf disks colonized was used as an indirect measure of zoospore activity in a solution. Therefore, quantitative comparisons among treatments could be made and the activity of zoospores over time could be evaluated. In the greenhouse experiment, data on leaf disk colo-
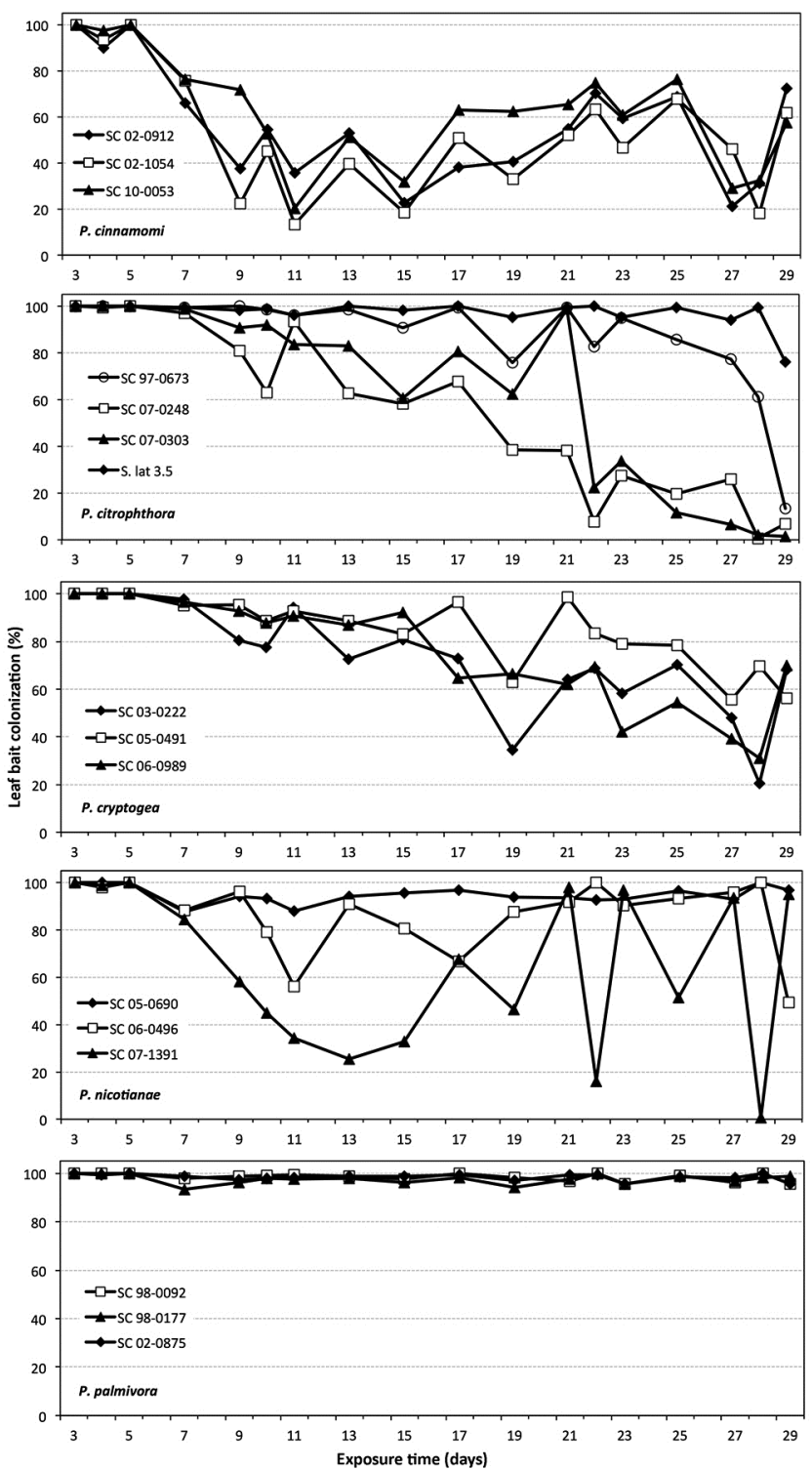

Fig. 1. Colonization of leaf disk baits while exposed for 29 days to zoospores released from agar plugs of three or four isolates of five species of Phytophthora. Data are means of six replicates from two trials. Percentage of the perimeter of each leaf bait that was colonized was estimated every 2 (trial 1) or 3 (trial 2) days. Specific isolates for each species are those listed in Table 3. 
nization was corroborated with zoospore density (i.e., direct enumeration of zoospores in $25-\mathrm{ml}$ aliquots of solution using a filtration assay).

Isolate identification. Morphological characteristics and molecular diagnostics confirmed the identities of all 16 isolates used in this study (Table 1). None of the isolates produced oospores in single-strain culture on scV8A after incubation for 6 weeks at $20^{\circ} \mathrm{C}$ in the dark. Therefore, all isolates were classified as heterothallic, which is consistent with the species identification of each isolate.

Laboratory experiment. Each of the 16 isolates produced zoospores and these zoospores were able to infect and colonize leaf baits throughout the 29-day exposure period used in all trials (Fig. 1). There was a significant interaction between the experimental factors exposure period (= time) and species (Table 3), indicating that bait colonization among the species of Phytophthora was not consistent over time. Likewise, colonization varied significantly over the 29-day exposure period and among isolates within a species (Table 3 ). These differences were evident when bait colonization by individual isolates was plotted over time (Fig. 1). Colonization of leaf baits was most variable among the isolates of $P$. citrophthora and $P$. nicotianae and did not differ significantly among the isolates of $P$. cinnamomi, $P$. cryptogea, and $P$. palmivora (Table 3; Fig. 1).

During the 29-day exposure period, leaf disk colonization among the three or four isolates of each of the five species of Phytophthora varied. Variability in the amount of leaf bait colonized increased over time and was most evident after 14 days for isolates of $P$. citrophthora, P. cryptogea, and P. nicotianae. Leaf disk colonization was much less variable over time among isolates of $P$. cinnamomi and $P$. palmivora; however, colonization of leaf baits by $P$. cinnamomi varied greatly over the 29 -day experiment, ranging from 100 to $15 \%$ of the perimeter colonized (Fig. 1). The ability of the five species of Phytophthora to release zoospores and colonize leaf baits varied somewhat when averaged over the entire exposure period but this difference was not significant $(P=0.087$, Table 3).

Greenhouse experiment. Based on results from the laboratory experiment, zoospore release from agar plugs was most consistent over the first 14 days; therefore, an exposure period of 13 days was used in this experiment. Leaf baits were infected by zoospores from all five species of Phytophthora throughout the 13-day exposure periods in trials conducted under both summer and winter conditions. However, leaf bait colonization by $P$. nicotianae and $P$. palmivora decreased steadily throughout the exposure periods during trials conducted in the winter (Fig. 2). During this experiment, the average air temperature in the greenhouse in winter was $13.5^{\circ} \mathrm{C}$ and in summer was $24.7^{\circ} \mathrm{C}$. Trials 1 and 2 in the summer had mean solution temperatures of $28.1 \pm 0.1$ and $25.1 \pm 0.1^{\circ} \mathrm{C}$ during the day and $25.4 \pm 0.1$ and $22.3 \pm 0.1^{\circ} \mathrm{C}$ at night, respectively. Trials 1 and 2 in the winter had mean solution temperatures of $15.5 \pm 0.2$ and $16.1 \pm 0.2^{\circ} \mathrm{C}$ during the day and $10.8 \pm 0.1$ and $10.7 \pm 0.1^{\circ} \mathrm{C}$ at night, respectively.

When bait colonization data over time (Fig. 2) were examined by ANOVA (Table 4), there were no interactions among the three experimental factors (species, time, and solution) in either summer or winter trials. However, there were differences in bait colonization over time in both winter $(P=0.020)$ and summer $(P=0.002)$ trials for all species of Phytophthora combined. There was also a difference in bait colonization among Phytophthora spp. in the two trials conducted in the winter $(P=0.029)$. Time was a significant factor in this experiment, with bait colonization decreasing over the 13-day exposure period in both summer and winter trials (Table 4). Colonization of leaf disks for all species combined over time was consistently better in Milli-Q water than in SES (Fig. 2); however, this difference was not statistically significant for either the summer or winter trials (Table 4). The difference between Milli-Q water and SES was most notable for P. citrophthora in the winter, when colonization of leaf baits floated on Milli-Q water was nearly $100 \%$ over the 13 days, whereas colonization of baits in SES varied between 40 and 60\% (Fig. 2). During winter trials, leaf bait colonization by $P$. nicotianae was significantly lower than that by $P$. cinnamomi and $P$. cryptogea, and colonization by $P$. palmivora was significantly lower than that by $P$. cinnamomi, $P$. citrophthora, and P. cryptogea (Table 4).

In addition to colonization of leaf baits, zoospore release in treatment solutions was verified by direct enumeration of CFU in 25-ml aliquots using a filtration assay. Zoospores of all five species were present throughout the 13-day exposure periods in trials conducted in both summer and winter, although more zoospores usually were present in the summer (Fig. 3). When filtration data were analyzed (Table 5), only one of the possible interactions among the three experimental factors (species, time, and solution) was significant (species-solution in summer, $P<$ $0.001)$. In the summer, zoospore densities were greater in Milli-Q water, decreased over time, and were highest for $P$. palmivora. In

Table 3. Differences among isolates within each of five species of Phytophthora for ability to release zoospores and colonize rhododendron leaf disks over a 29-day exposure period (= time) in the laboratory experiment ${ }^{\mathrm{x}}$

\begin{tabular}{|c|c|c|c|c|c|c|c|}
\hline \multirow[b]{2}{*}{ Species, effects } & \multicolumn{4}{|c|}{ Perimeter colonized $(\%)^{\mathrm{y}}$} & \multicolumn{3}{|c|}{ Two-way ANOVA ${ }^{z}$} \\
\hline & Isolate 1 & Isolate 2 & Isolate 3 & Isolate 4 & df & $F$ value & $P>F$ \\
\hline Phytophthora cinnamomi & $58 \mathrm{de}$ & $55 \mathrm{de}$ & 66 cde & & & & \\
\hline P. citrophthora & $85 a b c$ & $49 \mathrm{e}$ & $61 \mathrm{cde}$ & $97 \mathrm{a}$ & $\ldots$ & $\ldots$ & $\ldots$ \\
\hline P. cryptogea & 72 bcde & $83 a b c$ & 76 abcd & $\ldots$ & $\ldots$ & $\ldots$ & $\ldots$ \\
\hline P. nicotianae & 97 a & $90 \mathrm{ab}$ & $57 \mathrm{de}$ & $\ldots$ & $\ldots$ & $\ldots$ & $\ldots$ \\
\hline P. palmivora & 99 a & 99 a & 99 a & $\cdots$ & $\ldots$ & $\ldots$ & $\ldots$ \\
\hline \multicolumn{8}{|l|}{ Main effects } \\
\hline Species & $\ldots$ & $\ldots$ & $\ldots$ & $\ldots$ & 4 & 13.75 & 0.087 \\
\hline Isolates within a species & $\ldots$ & $\ldots$ & $\ldots$ & $\ldots$ & 11 & 5.24 & 0.047 \\
\hline Time & $\ldots$ & $\ldots$ & $\ldots$ & $\ldots$ & 17 & 7.90 & $<0.001$ \\
\hline Trial & $\ldots$ & $\ldots$ & $\ldots$ & $\ldots$ & 1 & 0.67 & 0.450 \\
\hline Error $_{\mathrm{A}}$ & $\cdots$ & $\ldots$ & $\ldots$ & $\cdots$ & 15 & $\ldots$ & $\ldots$ \\
\hline \multicolumn{8}{|l|}{ Two-way interactions } \\
\hline Species $\times$ time & $\ldots$ & $\ldots$ & $\ldots$ & $\ldots$ & 68 & 2.04 & 0.005 \\
\hline Isolates within a species $\times$ time & $\ldots$ & $\ldots$ & $\ldots$ & $\ldots$ & 187 & 0.62 & 0.986 \\
\hline Error $_{\mathrm{b}}$ & $\ldots$ & $\ldots$ & $\ldots$ & $\ldots$ & 11 & $\ldots$ & $\ldots$ \\
\hline
\end{tabular}

${ }^{\mathrm{x}}$ Three or four isolates (numbered 1 through 4) were used for each species. Agar plugs were placed in 260-ml plastic cups and covered with $150 \mathrm{ml}$ of nonsterile soil extract solution.

${ }^{y}$ Mean percentage of the perimeter of leaf baits colonized by an isolate of Phytophthora sp. for all sample times combined. Means of all 16 isolates were compared, and those with a letter in common are not significantly different based on Fisher's protected least significant difference (LSD) with an LSD value of $24(\alpha=0.05)$.

${ }^{\mathrm{z}}$ Results for two trials were combined, with three replicates of each treatment per trial. Data were analyzed by two-way analysis of variance (ANOVA) with trial as a random effect and repeated measures over time. 
the winter, zoospore densities were similar in both solutions, did not vary significantly over time, but did vary among species. $P$. citrophthora and $P$. cryptogea produced more zoospores under winter conditions in the greenhouse than did the other three species. Colonization of leaf disk baits and zoospore densities were not correlated $(P>0.05)$ in any of the four trials when correlation coefficients $(r)$ were calculated.

\section{Discussion}

In this study, a standard method of producing sporangia and small amounts of zoospores of Phytophthora spp. for taxonomic studies $(6,7,13)$ was used to produce a continuous supply of zoospores in aqueous solutions for up to 29 days. It is known that sporangia are produced on V8A plugs placed in solutions such as water and SES and that zoospores are released in 24 to $48 \mathrm{~h}(6,7,13)$ but the duration of zoospore release from a single set of flooded agar plugs has not been studied. In our study, colonization of rhododendron leaf disks floating on the surface of aqueous solutions was used as direct evidence that zoospores were present in these aqueous solutions. Likewise, the amount of the perimeter of the disks colonized was used as a measure of zoospore activity because zoospores are known to be both negatively geotropic and
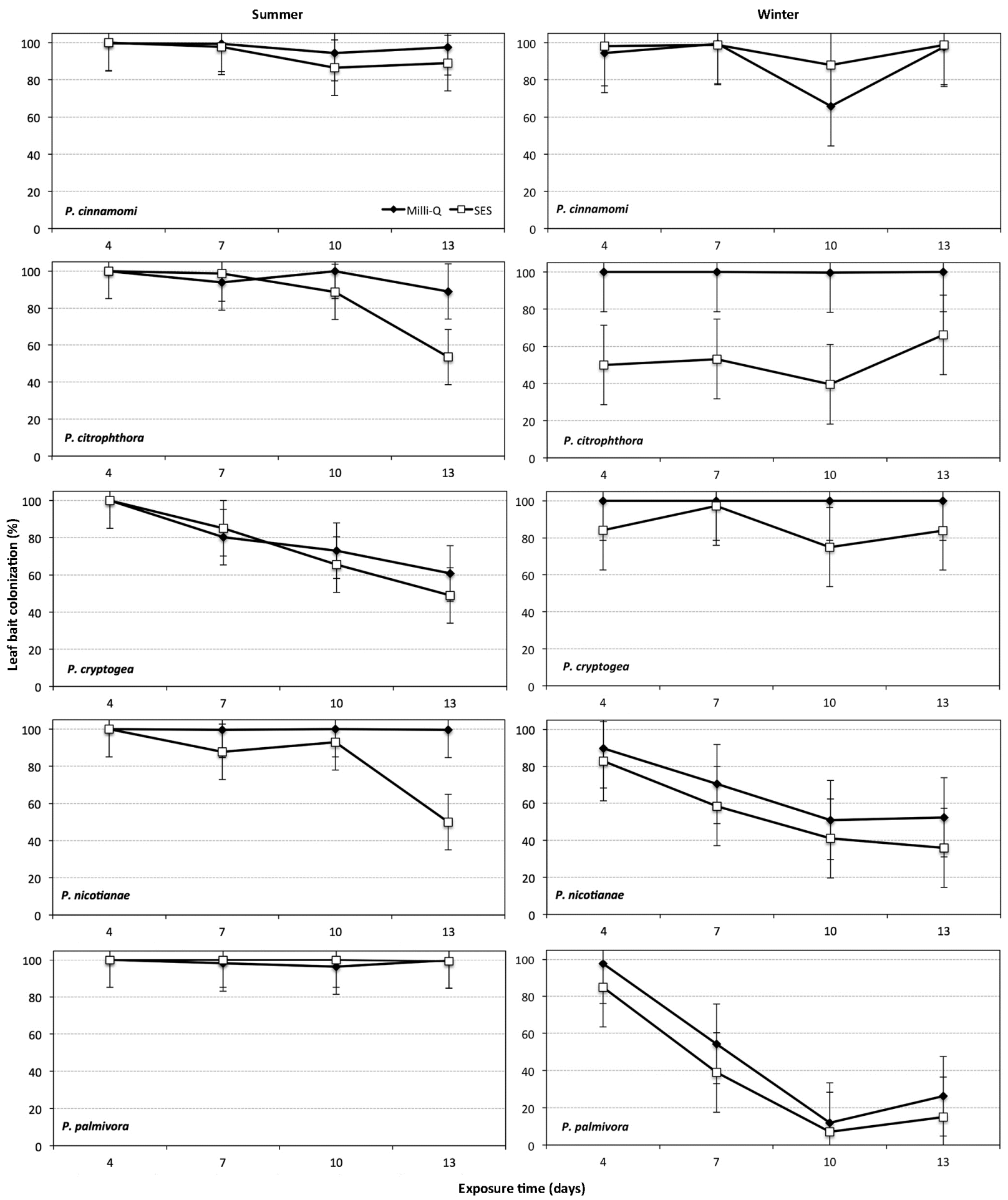

Fig. 2. Percent colonization of the perimeter of leaf disk baits during exposure for 13 days to zoospores of each of five species of Phytophthora in a greenhouse. Agar plugs from three or four isolates of a species were combined and placed in a container containing $1.5 \%$ nonsterile soil extract solution (SES) or Milli-Q water during summer and winter months. Data are means \pm standard errors $(n=6)$ from two trials. 
chemotactic, at least in laboratory studies (6). Therefore, once these propagules were released from sporangia into solution at the bottom of the containers, they rose to the surface and sought out susceptible host tissue (i.e., the rhododendron leaf disks that were used as baits). Therefore, a reduction in the percentage of the leaf disk perimeter colonized was attributed to either decreased zoospore release from agar plugs or reduction in the activity of the zoospores in solution. Interestingly, leaf disk colonization (percentage of perimeter colonized) and zoospore density (number of zoospores in $25 \mathrm{ml}$ of solution) were not significantly correlated when correlation coefficients were calculated. Therefore, number of zoospores in solution was closely related to amount of leaf bait tissue colonized. This probably is due to differences in virulence and aggressiveness among the isolates of the various species and also differences among species. These differences would affect the number of zoospores needed to infect leaf disks and the subsequent ability of an isolate to colonize leaf tissue. Overall, leaf bait colonization was a better measure of zoospore activity because it took into account both numbers of zoospores present in solution and the aggressiveness and virulence of individual isolates.

Bait colonization among isolates within a species of Phytophthora varied in the laboratory experiment, and this most likely was due to differences in zoospore density, differences in virulence and aggressiveness among isolates, or a combination of both. Zoospore densities were not determined in the laboratory experiment. Test isolates originated from a variety of host plants, and variation in virulence among isolates within a species of Phytophthora has been reported. For example, 40 isolates of $P$. nicotianae from an-

Table 4. Differences among five species of Phytophthora in ability to release zoospores and colonize rhododendron leaf baits in two aqueous solutions over a 13-day period (= time) in the greenhouse experiment, which was conducted in summer and winter months ${ }^{\mathrm{x}}$

\begin{tabular}{|c|c|c|c|c|}
\hline \multirow[b]{2}{*}{ Factor, level } & \multicolumn{2}{|c|}{$\begin{array}{c}\text { Perimeter } \\
\text { colonized }(\%)^{y}\end{array}$} & \multicolumn{2}{|c|}{$\begin{array}{l}\text { Three-way ANOVA } \\
(P>F)^{\mathrm{z}}\end{array}$} \\
\hline & Summer & Winter & Summer & Winter \\
\hline \multicolumn{5}{|l|}{ Species } \\
\hline Phytophthora cinnamomi & 95.5 & $92.6 \mathrm{a}$ & $\ldots$ & $\ldots$ \\
\hline P. cryptogea & 76.8 & $92.5 \mathrm{a}$ & $\ldots$ & $\ldots$ \\
\hline P. citrophthora & 90.6 & $76.1 \mathrm{ab}$ & $\ldots$ & $\ldots$ \\
\hline P. nicotianae & 91.2 & $60.2 \mathrm{bc}$ & $\ldots$ & $\ldots$ \\
\hline P. palmivora & 99.2 & $42.0 \mathrm{c}$ & $\ldots$ & $\ldots$ \\
\hline LSD & $\mathrm{ns}$ & 30.3 & $\ldots$ & $\ldots$ \\
\hline \multicolumn{5}{|l|}{ Time (days) } \\
\hline 4 & $100.0 \mathrm{a}$ & $88.1 \mathrm{a}$ & $\ldots$ & $\ldots$ \\
\hline 7 & $94.0 \mathrm{ab}$ & $77.1 \mathrm{ab}$ & $\ldots$ & $\ldots$ \\
\hline 10 & $89.7 \mathrm{~b}$ & $57.9 \mathrm{~b}$ & $\ldots$ & $\ldots$ \\
\hline 13 & $79.0 \mathrm{c}$ & $67.6 \mathrm{~b}$ & $\ldots$ & $\ldots$ \\
\hline LSD & 10.2 & 19.2 & $\ldots$ & $\ldots$ \\
\hline \multicolumn{5}{|l|}{ Solution } \\
\hline Milli-Q water & 94.1 & 80.5 & $\ldots$ & $\ldots$ \\
\hline Soil extract solution & 87.2 & 64.8 & $\ldots$ & $\ldots$ \\
\hline LSD & $\mathrm{ns}$ & ns & $\ldots$ & $\ldots$ \\
\hline \multicolumn{5}{|l|}{ ANOVA } \\
\hline Species & $\ldots$ & $\ldots$ & 0.656 & 0.029 \\
\hline Time & $\ldots$ & $\ldots$ & 0.002 & 0.020 \\
\hline Solution & $\ldots$ & $\ldots$ & 0.060 & 0.068 \\
\hline Species $\times$ time & $\ldots$ & $\ldots$ & 0.394 & 0.352 \\
\hline Species $\times$ solution & $\ldots$ & $\ldots$ & 0.519 & 0.284 \\
\hline Time $\times$ solution & $\ldots$ & $\ldots$ & 0.141 & 0.100 \\
\hline Species $\times$ time $\times$ solution & $\ldots$ & $\ldots$ & 0.950 & 0.100 \\
\hline
\end{tabular}

$\mathrm{x}$ Three or four isolates were used for each species. Agar plugs were placed in 1.9-liter plastic containers and covered with nonsterile soil extract solution or Milli-Q water.

${ }^{y}$ Mean percentage of the perimeter of leaf baits colonized by a species of Phytophthora. Data for summer and winter were analyzed separately. Means in each column with a letter in common are not significantly different based on Fisher's protected least significant difference (LSD; $P$ $=0.05) ; \mathrm{ns}=$ not significantly different.

${ }^{\mathrm{z}}$ Results for two trials were combined, with three replicates of each treatment per trial. Data were analyzed by three-way analysis of variance (ANOVA) with trial as a random effect and repeated measures over time. nual vinca varied in virulence when different cultivars of this host were inoculated (15), a worldwide collection of isolates of $P$. capsici varied in virulence when inoculated on the fruits of tomato and various cucurbits (8), and isolates of $P$. ramorum varied in virulence when coast live oak and California bay laurel were inoculated (11).

Leaf disk colonization by $P$. cinnamomi varied considerably over the 29-day exposure period in the laboratory experiment but bait colonization values among isolates of this species at specific sample times were similar. This uniform variation in zoospore activity among isolates may lie in the inherent biology of $P$. cinnamomi. $P$. cinnamomi is known to be a poor producer of sporangia in aquatic laboratory environments (6). It is possible that the three isolates of this species responded synchronously and produced sporangia and zoospores intermittently but consistently. More importantly, it is of interest that $P$. cinnamomi produced zoospores consistently in all trials of the two experiments conducted in this study, despite its reputation of limited sporangium production.

During the 29-day exposure periods in the laboratory experiment, all isolates of the five species of Phytophthora released zoospores that consistently infected rhododendron leaf baits. However, after 14 days, a general decline in leaf bait colonization and increased variation among isolates within species were observed. Therefore, the exposure period in the greenhouse experiment was reduced to 13 days. The greenhouse experiment was conducted in both summer and winter months to evaluate the effects of seasonal conditions on zoospore activity. Both bait colonization for some species and zoospore densities of all species were lower in winter

Table 5. Differences among five species of Phytophthora in numbers of zoospores (measured as CFU) in $25 \mathrm{ml}$ of treatment solution over a 13-day period in the greenhouse experiment, which was conducted in summer and winter months ${ }^{\mathrm{x}}$

\begin{tabular}{|c|c|c|c|c|}
\hline \multirow[b]{2}{*}{ Factor, level } & \multicolumn{2}{|c|}{ CFU $^{\mathbf{y}}$} & \multicolumn{2}{|c|}{$\begin{array}{l}\text { Three-way ANOVA } \\
\qquad(P>F)^{\mathrm{z}}\end{array}$} \\
\hline & Summer & Winter & Summer & Winter \\
\hline \multicolumn{5}{|l|}{ Species } \\
\hline Phytophthora cinnamomi & $18.6 \mathrm{~b}$ & $4.9 \mathrm{~b}$ & $\ldots$ & $\ldots$ \\
\hline P. citrophthora & $29.0 \mathrm{~b}$ & $12.0 \mathrm{a}$ & $\ldots$ & $\ldots$ \\
\hline P. cryptogea & $20.0 \mathrm{~b}$ & $13.0 \mathrm{a}$ & $\ldots$ & $\ldots$ \\
\hline P. nicotianae & $20.0 \mathrm{~b}$ & $6.5 \mathrm{~b}$ & $\ldots$ & $\ldots$ \\
\hline P. palmivora & $64.1 \mathrm{a}$ & $2.4 \mathrm{~b}$ & $\ldots$ & $\ldots$ \\
\hline LSD & 12.4 & 4.1 & $\ldots$ & $\ldots$ \\
\hline \multicolumn{5}{|l|}{ Time (days) } \\
\hline 4 & $41.0 \mathrm{a}$ & 8.3 & $\ldots$ & $\ldots$ \\
\hline 7 & $\mathrm{md}$ & 8.2 & $\ldots$ & $\ldots$ \\
\hline 13 & $19.7 \mathrm{~b}$ & 6.7 & $\ldots$ & $\ldots$ \\
\hline LSD & 7.8 & ns & $\ldots$ & $\ldots$ \\
\hline \multicolumn{5}{|l|}{ Solution } \\
\hline Milli-Q water & $45.6 \mathrm{a}$ & 8.3 & $\ldots$ & $\ldots$ \\
\hline Soil extract solution & $15.1 \mathrm{~b}$ & 7.2 & $\ldots$ & $\ldots$ \\
\hline LSD & 7.8 & ns & $\ldots$ & $\ldots$ \\
\hline \multicolumn{5}{|l|}{ ANOVA } \\
\hline Species & $\ldots$ & $\ldots$ & $<0.001$ & 0.007 \\
\hline Time & $\ldots$ & $\ldots$ & $<0.001$ & 0.963 \\
\hline Solution & $\ldots$ & $\ldots$ & $<0.001$ & 0.474 \\
\hline Species $\times$ time & $\ldots$ & $\ldots$ & 0.113 & 0.694 \\
\hline Species $\times$ solution & $\ldots$ & $\ldots$ & $<0.001$ & 0.140 \\
\hline Time $\times$ solution & $\ldots$ & $\ldots$ & 0.112 & 0.837 \\
\hline Species $\times$ time $\times$ solution & $\ldots$ & $\ldots$ & 0.096 & 0.290 \\
\hline
\end{tabular}

${ }^{x}$ Three or four isolates were used for each species. Agar plugs were placed in 1.9-liter plastic containers and covered with nonsterile soil extract solution or Milli-Q water.

${ }^{y}$ Number of CFU present in a solution was determined by filtration. Data for summer and winter were analyzed separately. Means in each column with a letter in common are not significantly different based on Fisher's protected least significant difference (LSD; $P=0.05$ ); $\mathrm{md}=$ missing datum because water samples were not collected at 7 days in the summer trials; ns = not significantly different.

${ }^{\mathrm{z}}$ Results for two trials were combined, with three replicates of each treatment per trial. Data were analyzed by three-way analysis of variance (ANOVA), with trial as a random effect and repeated measures over time. 
trials than in summer trials. Temperatures in the greenhouse were lower in the winter than in the summer, and this resulted in lower solution temperatures, which may have affected production of sporangia or activity of zoospores. In particular, bait colonization by $P$. nicotianae and $P$. palmivora declined through the 13-day exposure periods in the winter trials, and bait colonization in SES by $P$. citrophthora was relatively low throughout the winter trials. The optimum growing temperatures for $P$. nicotianae and $P$. palmivora are 25 to $30^{\circ} \mathrm{C}(6,27)$ and the average temperature of container solutions during our winter trials was only $13^{\circ} \mathrm{C}$.

The gradual decline of leaf disk colonization by $P$. cryptogea during the summer trials in the greenhouse may also be attributed to solution temperature. Bait colonization for P. cryptogea during summer trial 1 was significantly different from that in summer trial 2 (data not presented). The decline in ability to infect leaf baits was only observed during the first summer trial, when the average temperature of container solutions was $28^{\circ} \mathrm{C}$ during the day and $25^{\circ} \mathrm{C}$ at night, with extended periods of solution temperatures above $30^{\circ} \mathrm{C}$. Previously, MacDonald and Duniway (16) reported that prolonged exposure to temperatures $\geq 30^{\circ} \mathrm{C}$ resulted in a consistent decline in the ability of sporangia of $P$. cryptogea to discharge zoospores. The optimum temperature for growth for $P$. cryptogea is 20 to $25^{\circ} \mathrm{C}$, with the upper limits for zoospore release being $33^{\circ} \mathrm{C}(6,16)$. Consequently, excessive daytime solution temperatures during the first summer trial may have adversely affected zoospore release by $P$. cryptogea. Mean daytime water tempera-
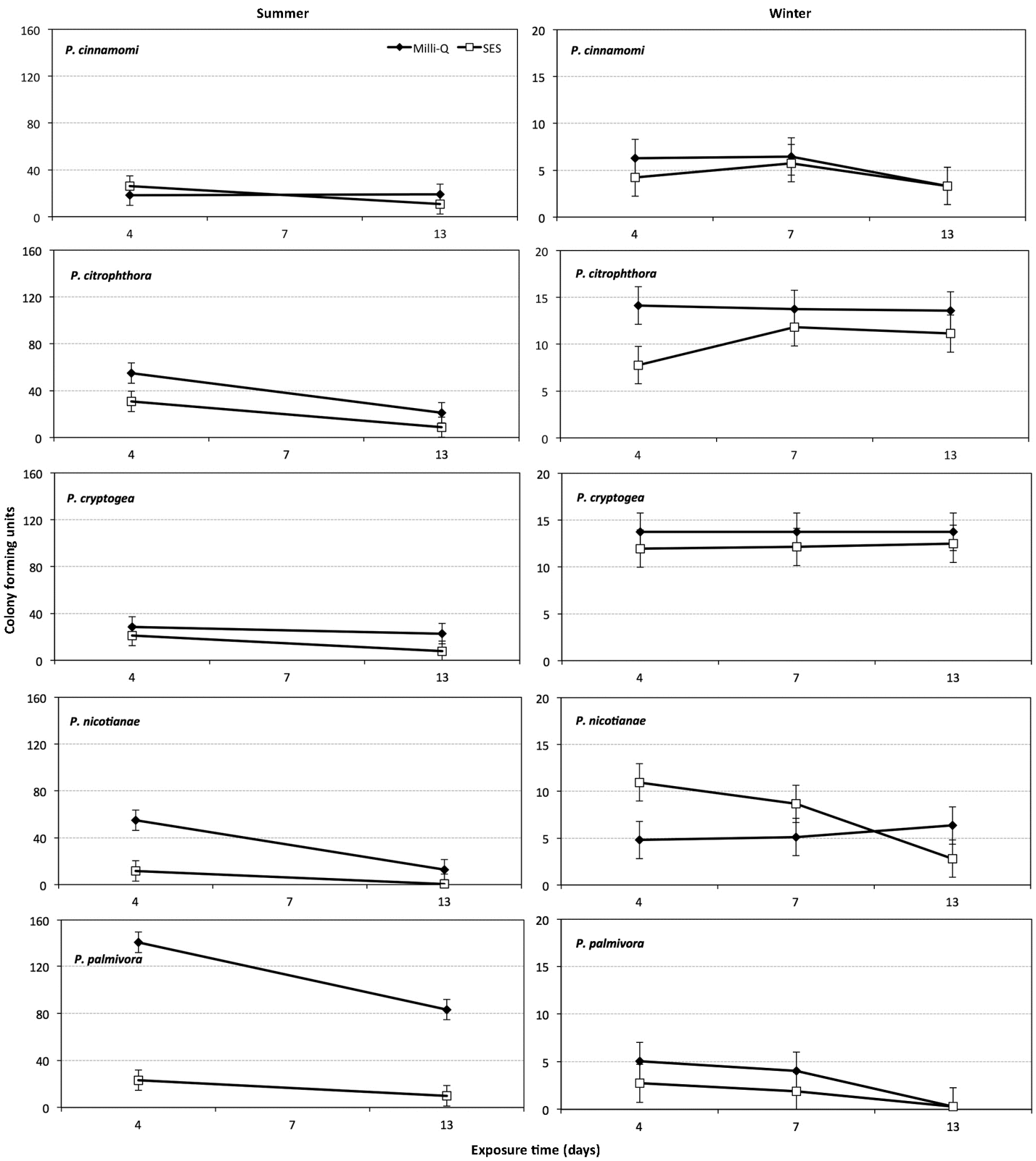

Fig. 3. Numbers of zoospores produced by five species of Phytophthora and present in $25 \mathrm{ml}$ of treatment solution during summer and winter months in the greenhouse experiment. Solutions were sampled twice in one summer trial $(n=3)$ and three times in two winter trials $(n=6)$ over a 13-day period. Numbers were determined by filtration and data are mean numbers of $\mathrm{CFU} \pm$ standard errors. Scales for the y-axes for winter and summer graphs are different. 
tures during the second summer trial were $25^{\circ} \mathrm{C}$ during the day and $22^{\circ} \mathrm{C}$ at night, and no decline in leaf disk colonization by P. cryptogea was recorded during this trial.

The type of treatment solution seemed to affect the number of zoospores present in these solutions, with greater densities of zoospores present in Milli-Q water than in SES. This was particularly true for $P$. palmivora during the summer trials; however, leaf bait colonization was not adversely affected. This disparity leads one to wonder how much inoculum must be present to cause infection. During the winter, infection of leaf baits was more variable than in summer and lower numbers of zoospores were present in both solutions; therefore, reduced zoospore availability may have contributed to this increased variability.

It is unclear why both zoospore density and bait colonization were reduced in SES compared with Milli-Q water. SES commonly is used to induce sporangium formation in the laboratory $(6,7,13)$; therefore, we presumed it would work as well as, or better than, Milli-Q water in the greenhouse environment; however, this was not the case. Some potential explanations could involve either competition or interaction with the microbial population or a negative influence of salts or other ions in the SES. Because Milli-Q is ultrafiltered water, there were no or very few microbes and few chemical contaminants present to affect sporangium formation and zoospore survival.

This research was conducted to develop a method to inoculate wetland plants used in vegetative buffers and constructed wetlands so that these plants could be evaluated for potential susceptibility to species of Phytophthora present in runoff water at nurseries growing ornamental plants in the southeastern United States. We have successfully developed a routine inoculation procedure that can be used in future studies investigating potential susceptibility. Plants can be exposed to zoospores of the five species of Phytophthora used in this study ( $P$. cinnamomi, $P$. citrophthora, $P$. cryptogea, $P$. nicotianae, and $P$. palmivora) but other species of Phytophthora easily could be included. At least three isolates of each species and three V8A plugs from actively growing cultures of each isolate should be used because isolates were shown to vary in ability to colonize baits. Isolates of the same species can be pooled but it would be interesting to determine whether isolates of different species also could be combined to streamline the procedure. Fresh agar plugs should be added to each container every 14 days throughout the test period to maintain adequate levels of inocula. Wetland plant species should be exposed to species of Phytophthora during both summer and winter months because zoospores of all species were most abundant during summer but cooler winter temperatures may be more favorable to some species of Phytophthora.

\section{Acknowledgments}

This study was supported financially by the United States Department of Agriculture-Agricultural Research Service (USDA-ARS) specific cooperative agreement number 58-6618-2-105 for "Use of Wetland Systems to Treat Nursery Runoff", which is part of the USDA-ARS Floriculture and Nursery Research Initiative. We thank all of those who helped with the various aspects of this project, including laboratory and greenhouse work: I. M. Meadows, L. A. Luszcz, S. Schreier, J. Hwang, and R. Gossett.

\section{Literature Cited}

1. Benson, D. M., and von Broembsen, S. 2001. Phytophthora root rot and dieback. Pages 52-56 in: Diseases of Woody Ornamentals and Trees in Nurseries. R. K. Jones and D. M. Benson, eds. American Phytopathological Society, St. Paul, MN.

2. Bowers, J. H., Martin, F. N., Tooley, P. W., and Luz, E. D. M. N. 2007. Genetic and morphological diversity of temperate and tropical isolates of Phytophthora capsici. Phytopathology 97:492-503.

3. Bowman, D. B., Albrecht, U., Graham, J. H., and Bright, D. B. 2007. Detection of Phytophthora nicotianae and P. palmivora in citrus roots using PCRRFLP in comparison with other methods. Eur. J. Plant Pathol. 119:143-158.

4. Bush, E. A., Hong, C. X., and Stromberg, E. L. 2003. Fluctuations of Phytophthora and Pythium spp. in components of a recycling irrigation system. Plant Dis. 87:1500-1506.
5. Cooke, D. E. L., Duncan, J. M., Williams, N. A., Hagenaar-de Weerdt, M., and Bonants, P. J. M. 2000. Identification of Phytophthora species on the basis of restriction enzyme fragment analysis of the internal transcribed spacer regions of ribosomal RNA. Bull. OEPP/EPPPO Bull. 30:519-523.

6. Erwin, D. C., and Ribeiro, O. K. 1996. Phytophthora Diseases Worldwide. American Phytopathological Society, St. Paul, MN.

7. Ferguson, A. J., and Jeffers, S. N. 1999. Detecting multiple species of Phytophthora in container mixes from ornamental crop nurseries. Plant Dis. 83:1129-1136.

8. Granke, L. L., Quesada-Ocampo, L. M., and Hausbeck, M. K. 2012. Differences in virulence of Phytophthora capsici isolates from a worldwide collection on host fruits. Eur. J. Plant Pathol. 132:281-296.

9. Grünwald, N. J., Goss, E. M., and Press, C. M. 2008. Phytophthora ramorum: a pathogen with a remarkably wide host range causing sudden oak death on oaks and ramorum blight on woody ornamentals. Mol. Plant Pathol. 9:729-740.

10. Holmes, K. A., and Benson, D. M. 1994. Evaluation of Phytophthora parasitica var. nicotianae as a biocontrol for Phytophthora parasitica on Catharanthus roseus. Plant Dis. 78:193-199.

11. Huberli, D., and Garbelotto, M. 2012. Phytophthora ramorum is a generalist plant pathogen with differences in virulence between isolates from infectious and dead-end hosts. For. Pathol. 42:8-13.

12. Hwang, J., Oak, S. W., and Jeffers, S. N. 2006. Monitoring occurrence and distribution of Phytophthora species in forest streams in western North Carolina. (Abstr.) Phytopathology 96:S52.

13. Jeffers, S. N., and Aldwinckle, H. S. 1987. Enhancing detection of Phytophthora cactorum in naturally infested soil. Phytopathology 77:14751482.

14. Jeffers, S. N., and Aldwinckle, H. S. 1988. Phytophthora crown rot of apple trees: sources of Phytophthora cactorum and P. cambivora as primary inoculum. Phytopathology 78:328-335.

15. Jeffers, S. N., and Meadows, I. M. 2011. Variation in virulence among isolates of Phytophthora nicotianae recovered from Catharanthus roseus. (Abstr.) Phytopathology 101:S266.

16. MacDonald, J. D., and Duniway, J. M. 1978. Temperature and water stress effects on sporangium viability and zoospore discharge in Phytophthora cryptogea and $P$. megasperma. Phytopathology 68:1449-1455.

17. Moltzan, B., Pfister, S., Lydick, J., Daoust, D., Britton, K., and Duerr, D. 2012. National Framework for Managing Sudden Oak Death Caused by Phytophthora ramorum in Forests and Wildlands. U.S. For. Serv., APHIS, Nat. Assoc. State For., Natl. Plant Board.

18. Olson, H. A., and Benson, D. M. 2011. Characterization of Phytophthora spp. on floriculture crops in North Carolina. Plant Dis. 95:1013-1020.

19. Olson, H. A., Jeffers, S. N., Ivors, K. L., Steddom, K. C., Williams-Woodward, J. L., Mmbaga, M. T., Benson, D. M., and Hong, C. X. 2013. Diversity and mefenoxam sensitivity of Phytophthora spp. associated with the ornamental horticulture industry in the southeastern United States. Plant Dis 97:86-92.

20. Park, J., Park, B., Veeraraghavan, N., Jung, K., Lee, Y.-H., Blair, J. E., Geiser, D. M., Isard, S., Mansfield, M. A., Nikolaeva, E., Park, S.-Y., Russo, J., Kim, S. H., Greene, M., Ivors, K. L., Balci, Y., Peiman, M., Erwin, D. C., Coffey, M. D., Rossman, A., Farr, D., Cline, E., Grünwald, N. J., Luster, D. G., Schrandt, J., Martin, F., Ribeiro, O. K., Makalowska, I., and Kang, S. 2008. Phytophthora Database: a forensic database supporting the identification and monitoring of Phytophthora. Plant Dis. 92:966-972.

21. Parke, J. L., and Grünwald, N. J. 2012. A systems approach for management of pests and pathogens of nursery crops. Plant Dis. 96:1236-1244.

22. Ridge, G. A., White, S. A., Meadows, I. M., and Jeffers, S. N. 2012. Developing a method to evaluate plants used in constructed wetlands for susceptibility to five species of Phytophthora. South. Nursery Assoc. Res. Conf. Proc. 57:251-256.

23. Rizzo, D. M., Garbelotto, M., Davidson, J. M., Slaughter, G. W., and Koike, S. T. 2002. Phytophthora ramorum as the cause of extensive mortality of Quercus spp. and Lithocarpus densiflorus in California. Plant Dis. 86:205214.

24. Roiger, D. J., and Jeffers, S. N. 1991. Evaluation of Trichoderma spp. for biological control of Phytophthora crown and root rot of apple seedlings. Phytopathology 81:910-917.

25. Schwingle, B. W., Smith, J. A., and Blanchette, R. A. 2007. Phytophthora species associated with diseased woody ornamentals in Minnesota nurseries. Plant Dis. 91:97-102.

26. Taylor, M. D., White, S. A., Chandler, S. L., Klaine, S. J., and Whitwell, T. 2006. Nutrient management of nursery runoff water using constructed wetland systems. HortTechnology 16:610-614.

27. Timmer, L. W., Zitko, S. E, Gottwald, T. R., Graham, J. H. 2000. Phytophthora brown rot of citrus: temperature and moisture effects on infection, sporangium production, and dispersal. Plant Dis. 84:157-163.

28. Vymazal, J. 2011. Constructed wetlands for wastewater treatment: five decades of experience. Environ. Sci. Technol. 45:61-69.

29. Weste, G., and Marks, G. C. 1987. The biology of Phytophthora cinnamomi in Australasian forests. Annu. Rev. Phytopathol. 25:207-229. 